\title{
BMJ Endoscopic retrograde Open cholangiopancreatography: utilisation and outcomes in a 10-year population-based cohort
}

\author{
Nayantara Coelho-Prabhu, ${ }^{1}$ Nilay D Shah, ${ }^{2}$ Holly Van Houten, ${ }^{2}$ Patrick S Kamath, ${ }^{1}$ \\ Todd H Baron ${ }^{1}$
}

To cite: Coelho-Prabhu N, Shah ND, Van Houten $\mathrm{H}$, et al. Endoscopic retrograde cholangiopancreatography: utilisation and outcomes in a 10-year population-based cohort. BMJ Open 2013;3: e002689. doi:10.1136/ bmjopen-2013-002689

- Prepublication history for this paper is available online. To view these files please visit the journal online (http://dx.doi.org/10.1136/ bmjopen-2013-002689).

Received 2 February 2013 Revised 25 April 2013 Accepted 29 April 2012

This final article is available for use under the terms of the Creative Commons Attribution Non-Commercial 2.0 Licence; see http://bmjopen.bmj.com

\footnotetext{
${ }^{1}$ Division of Gastroenterology and Hepatology, Mayo Clinic, Rochester, Minnesota, USA ${ }^{2}$ Division of Health Care Policy and Research, Mayo Clinic, Rochester, Minnesota, USA

Correspondence to Dr Nayantara Coelho-Prabhu; Coelhoprabhu.nayantara@ mayo.edu
}

\section{ABSTRACT}

Objective: To determine utilisation of endoscopic retrograde cholangiopancreatography (ERCP); incidence of inpatient admissions for complications occurring within 30 days of ERCP and risk factors for procedural-related complications, in a population-based study.

Design: Retrospective cohort study.

Setting: Olmsted County, Minnesota.

Participants: All adult residents of Olmsted County, Minnesota, who underwent ERCP from 1997 to 2006.

Interventions: Diagnostic and therapeutic ERCPS

were assessed.

Primary and secondary outcome measures:

Patient and procedural characteristics and complications within 30 days; and rates of ERCP utilisation and unplanned admissions and risk factors for admissions.

Results: In 10 years, 1072 ERCPs were performed on 827 individual patients. Average utilisation of ERCP was $83.1 \mathrm{ERCPs} / 100000$ persons/year, with an increase from 58 to $104.8 \mathrm{ERCPs} / 100000$ persons/ year over time, driven by increases in therapeutic procedures. Within 30 days after 236 procedures, 62 admissions were definitely related to the index ERCP. The complication rate was $5.3 \%$, including pancreatitis $(26,2.4 \%)$, infection/cholangitis $(16,1.5 \%)$, bleeding $(15,1.4 \%)$ and perforation $(4,0.37 \%)$. 30-day mortality was $2.4 \%$, none of which was directly related to the ERCP or complications thereof. Risk factors identified through multivariate analysis to be associated with adverse events included: age $<45$ years $(p=0.0498)$; body mass index $\geq 35$ $(p=0.0024) ;$ pancreatic duct cannulation ( $p=0.0026)$; outpatient procedure $(p<0.0001)$; intraprocedure sphincterotomy bleeding $(p<0.0001)$; difficulty grade $(p=0.115)$ and patient's first ERCP $(p=0.0394)$.

Limitations: Retrospective study.

Conclusions: Population utilisation of ERCP rose during the study period, specifically in therapeutic procedures. Admissions within 30 days of ERCP are common but often unrelated. Complications of ERCP remain infrequent and deaths quite unusual.

\section{ARTICLE SUMMARY}

\section{Article focus}

- Owing to the increasing use of quality metrics, accurate measures of utilisation and procedural adverse event (AE) risks are necessary to establish benchmarks for quality, and are best determined from community-based studies.

- There are no reports of community-based utilisation of ERCP in the USA.

- The aims of this population-based study were to determine the utilisation of ERCP including changes over time, the incidence of inpatient admissions for AEs within 30 days of ERCP and risk factors for procedural-related AEs.

Key messages

- Population utilisation of ERCP in Olmsted County, Minnesota rose over the 10-year period from 1997 to 2006, driven specifically by increases in therapeutic procedures. The most common indications for ERCP were therapy of choledocholithiasis and to determine aetiology of acute pancreatitis.

- Admissions within 30 days after ERCP are common, but are usually unrelated. Complications of ERCP remain infrequent at $5.3 \%$ and no deaths were directly related.

- Risk factors associated with AEs from ERCP include younger age, BMI $\geq 35$, pancreatic duct cannulation, outpatient procedures, intraprocedure sphincterotomy bleeding, difficulty grade and patient's first ERCP.

\section{BACKGROUND}

Since its first description in 1968, endoscopic retrograde cholangiopancreatography (ERCP) has become an established modality for the diagnosis and treatment of pancreaticobiliary disorders. $^{1} 2$ Over the years, ERCP has evolved from a purely diagnostic to a mainly therapeutic procedure. Around 500000 ERCPs are performed annually in the USA 


\section{ARTICLE SUMMARY}

Strengths and limitations of this study

- Population-based epidemiological research can be conducted in Olmsted County because medical care is virtually selfcontained within the community.

- The unique advantage of our data is that Mayo Clinic is the only centre performing ERCP in the entire county, and therefore population-based utilisation and AES of ERCP with full details of procedures and subsequent hospitalisations can be assessed.

- The study is a retrospective review with inherent potential biases.

- The skills of the endoscopists are most likely at a higher level than those of endoscopists in smaller community hospitals. Therefore, the AE rate in this community setting could be lower than one would expect in other community settings.

with adverse event (AE) rates between $4 \%$ and $10 \%,{ }^{3}$ and mortality between $0.05 \%$ and $1 \% .^{4-7}$ The most common AEs following ERCP include pancreatitis, haemorrhage and infection, which occurred in $4 \%$ to7\% of procedures. ${ }^{3} 68$ There is an increased risk of AEs after therapeutic procedures and in patients with suspected Sphincter of Oddi dysfunction. ${ }^{6}$ Since ERCP is an endoscopic procedure with the highest cost and AE rates, diagnostic ERCP is now avoided in favour of other diagnostic modalities such as less-invasive endoscopic ultrasound (EUS) and non-invasive MR cholangiopancreatography (MRCP). ${ }^{2} \quad{ }^{3} \quad{ }^{9}$ In an era of increasing utilisation of quality metrics, accurate measures of utilisation rates and procedural $\mathrm{AE}$ risks are necessary to establish meaningful benchmarks for quality, and are best determined from community-based studies.

There are no reports of community-based utilisation of ERCP in the USA, but there are several from Europe. ${ }^{8}{ }^{10}$ Published reports of ERCP-related AEs have all been single-centred or multicentred studies from tertiary care centres and affected by referral bias, leading to high estimates of risk that may not apply to the general population. All AEs of procedures performed at tertiary care centres may not be captured since the patients may seek care for AEs closer to their homes and thus be lost to follow-up.

The aims of this population-based study were to determine (1) the utilisation of ERCP, including changes over time; (2) the incidence of inpatient admissions for AEs within 30 days of ERCP and (3) risk factors for procedural-related AEs among residents of Olmsted County, Minnesota over a 10-year period from 1997 to 2006. The findings of this study are unique, as they represent population-based estimates of utilisation and risks associated with ERCP and may serve as more accurate and clinically meaningful data for clinical decisionmaking and development of quality benchmarks.

\section{METHODS}

\section{Study design}

A retrospective cohort study was conducted with the approval of the Institutional Review Board of Mayo Clinic in compliance with federal regulations of the U.S. Department of Health and Human Services for protection of human subjects and the Health Information Protection and Portability Act. All patients provided consent for medical record review. Billing records from Mayo Clinic and associated hospitals were queried for Olmsted County residents who had undergone an ERCP during a 10-year period from 1 January 1997 to 31 December 2006. ERCPs were identified using CPT codes for ERCP, including 43260, 43261, 43262, 43263, 43264, 43265, 43267, 43268, 43269, 43271, 43272 and 47999. Utilisation characteristics for EUS were determined in the same population using codes 43232, 43238 and 43242 and for MRCP using codes 74181, 74182 and 74183. Patients also had to be age $\geq 18$ years, live in Olmsted County and have valid authorisation to review medical records for research purposes in accordance with Minnesota State statutes.

Population-based epidemiological research can be conducted in Olmsted County because medical care is virtually self-contained within the community. Olmsted County comprises over 100000 persons, of whom $85 \%$ are Caucasian and $50 \%$ are women; sociodemographically, the community is similar to the US population. Over half of the county's population is seen at one of the Mayo Clinic facilities; $95 \%$ of local residents will have had at least one medical contact with a local care provider (eg, for dental x-rays, sports physical examinations, pre-employment examinations, minor illness and routine medical care) during any 4 -year period. ${ }^{11}$ Mayo Clinic has a common medical record system with its two affiliated hospitals (Saint Mary's and Rochester Methodist) for 90 years. Mayo Clinic's single record system contains both inpatient and outpatient data. The diagnoses and surgical procedures recorded in these records are indexed. It includes diagnoses made for outpatients seen in office or clinic consultations, emergency room visits, and diagnoses recorded for hospital inpatients, autopsy examinations or on death certificates. The unique advantage of our data is that Mayo Clinic is the only centre performing ERCP in the entire county, and therefore population-based utilisation and AEs of ERCP with full details of the hospitalisation can be assessed.

Medical records were reviewed retrospectively by the primary author. Patient and procedural characteristics, as well as AEs within 30 days, were recorded. As many as 170 variables were collected for each procedure and recorded into a database.

Primary outcomes measured were (1) utilisation rates of unique ERCP procedures in the adult population (age 18 years and older) of Olmsted County from 1997 to 2006, and (2) the rate of unplanned admissions within 30 days following ERCP for ERCP-related AEs. Secondary outcomes included patient and procedural 


\section{Table 1 Morriston Hospital ERCP grading scale ${ }^{13}$}

\begin{tabular}{l}
\hline Procedure \\
\hline Diagnostic ERCP \\
Biliary sphincterotomy, balloon sphincteroplasty, removal of extrahepatic stones $\leq 1 \mathrm{~cm}$ using basket and/or balloon \\
Precut sphincterotomy, large stones removal $(>1 \mathrm{~cm})$, intrahepatic stone removal, mechanical lithotripsy, stricture \\
dilation, cytology, stent insertion and nasobiliary drain \\
Sphincter of Oddi manometry, diagnostic and therapeutic ERCP after Billroth II surgery, minor papilla \\
sphincterotomy, endoscopic ampullectomy and all pancreatic duct therapeutic procedures. Cholangioscopy, laser \\
lithotripsy, electrohydraulic lithotripsy, combined procedures (PTC and ERCP) and other advanced bile duct \\
therapeutic procedures \\
\hline ERCP, endoscopic retrograde cholangiopancreatography; PTC, percutaneous transhepatic cholangiography.
\end{tabular}

characteristics, predictive of having an unplanned admission within 30 days after ERCP for an ERCP-related AE.

Utilisation metrics included the patients' age, sex, race, Charlson score at the time of ERCP, ${ }^{12}$ body mass index (BMI), cholecystectomy within 30 days prior to ERCP, altered anatomy (including gastrojejunostomy, Whipple anatomy, hepaticojejunostomy and choledochojejunostomy), presence of cirrhosis and previous history of ERCP. Indications for ERCP were then examined as biliary versus pancreatic, diagnostic versus therapeutic and graded for complexity using the previously published Morriston Hospital ERCP grading scale (table 1). ${ }^{13}$ Diagnostic procedures had a CPT code of 43260 where no intervention was performed, other than a cholangiogram or pancreatogram; all other procedures were therapeutic. Multiple intraprocedural details, including the presence of a trainee, type and amount of sedation used, and biliary and pancreatic ductal interventions were noted. Success of the procedure was recorded as the ability to cannulate the intended duct and achieve the intended therapy.
AEs recorded included unplanned admissions; sedation-related events, including pulmonary and cardiovascular events; infection; pancreatitis; bleeding; perforation; need for repeat endoscopic procedure or mortality within 30 days. These outcomes were determined as being related to the index ERCP by author review. AEs were deemed to be definitely related, probably related, possibly related or definitely unrelated to the index ERCP. Possibly related AEs included patients admitted with abdominal pain, but without evidence of definite pancreatitis by laboratory studies or documented cholangitis. Probably related AEs included biliary or pancreatic stent dysfunction leading to a repeat of the procedure within 30 days of the index procedure, but without any of the defined AEs of pancreatitis, infection, perforation and gastrointestinal bleeding. The latter AEs were categorised as mild, moderate and severe, according to established consensus criteria (table 2) ${ }^{6} \quad{ }^{14}$ Patients undergoing elective surgery including cholecystectomy within 30 days of ERCP were also identified.

Table 2 Consensus criteria for endoscopic retrograde cholangiopancreatography complications ${ }^{14}$

\begin{tabular}{|c|c|c|c|}
\hline & Mild & Moderate & Severe \\
\hline Bleeding & $\begin{array}{l}\text { Clinical evidence of bleeding (ie, not } \\
\text { just endoscopic) } \\
\text { Haemoglobin drop }<3 \mathrm{~g} \\
\text { No need for transfusion }\end{array}$ & $\begin{array}{l}\text { Transfusion: } 4 \text { units or less } \\
\text { No angiographic intervention or } \\
\text { surgery }\end{array}$ & $\begin{array}{l}\text { Transfusion: } 5 \text { units or more or } \\
\text { intervention (angiographic or } \\
\text { surgical) }\end{array}$ \\
\hline Perforation & $\begin{array}{l}\text { Possible, or only very slight leak of } \\
\text { fluid or contrast dye } \\
\text { Treatable by fluids and suction for } \\
3 \text { days or less }\end{array}$ & $\begin{array}{l}\text { Any definite perforation treated } \\
\text { medically for } 4-10 \text { days }\end{array}$ & $\begin{array}{l}\text { Medical treatment for more than } \\
10 \text { days or intervention } \\
\text { (percutaneous or surgical) }\end{array}$ \\
\hline Pancreatitis & $\begin{array}{l}\text { Clinical pancreatitis: amylase at least } \\
\text { thrice the upper limit of normal at } \\
\text { more than } 24 \mathrm{~h} \text { after the procedure } \\
\text { requiring admission or prolongation } \\
\text { of planned admission to } 2-3 \text { days }\end{array}$ & $\begin{array}{l}\text { Pancreatitis requiring } \\
\text { hospitalisation for } 4-10 \text { days }\end{array}$ & $\begin{array}{l}\text { Pancreatitis requiring } \\
\text { hospitalisation for more than } \\
10 \text { days, or haemorrhagic } \\
\text { pancreatitis, phlegmon or } \\
\text { intervention (percutaneous } \\
\text { drainage or surgery) }\end{array}$ \\
\hline $\begin{array}{l}\text { Infection } \\
\text { (cholangitis) }\end{array}$ & $>38^{\circ} \mathrm{C}$ at $24-48 \mathrm{~h}$ & $\begin{array}{l}\text { Febrile or septic illness requiring } \\
>3 \text { days of hospital treatment or } \\
\text { endoscopic or percutaneous } \\
\text { intervention }\end{array}$ & Septic shock or surgery \\
\hline
\end{tabular}




\section{Statistical analysis}

Univariate analyses were performed to obtain descriptive statistics for patient and procedural characteristics. Annual incidence was determined by dividing the number of ERCPs performed on the study subjects during a calendar-year by the adult population of Olmsted County during that period, according to County records and normalised to 100000 persons. To test for associations between patient and procedural characteristics and ERCP-related AEs, values of these characteristics were compared between participants who experienced ERCP-related AEs and participants who did not by two sample t tests for continuous variables, and $\chi^{2}$ test for discrete variables. Multivariable logistic regression analyses were used to determine patient and procedural characteristics predictive of ERCP-related AEs. $\mathrm{p}$ Values less than 0.05 were considered to be statistically significant. All analyses for this study were conducted using SAS statistical software (SAS V.9.1 for Windows; SAS Institute Inc, Cary, North Carolina, USA).

\section{RESULTS}

\section{Demographic characteristics}

In the 10-year period from 1 January 1997 to 31 December 2006, 1072 ERCPs were performed on 827 individual adult residents of Olmsted County. The total number of ERCPs carried out during this time period was 13056 including the non-residents of Olmsted County. Patient demographic characteristics can be seen in table 3. Prior to the index cholecystectomy, 232 (28\%) patients had a previous cholecystectomy; 21 (2\%) patients had altered anatomy and $20(1.9 \%)$ were taking clopidogrel or warfarin at the time of ERCP. There were 153 patients who had more than one ERCP during the

\begin{tabular}{|c|c|}
\hline \multicolumn{2}{|c|}{ Age at time of ERCP (years) } \\
\hline Mean (SD) & $57.6(19.8)$ \\
\hline $18-44$ & $283(26.4 \%)$ \\
\hline $45-64$ & $357(33.3 \%)$ \\
\hline$>65+$ & $432(40.3 \%)$ \\
\hline \multicolumn{2}{|l|}{ Gender } \\
\hline Female, n (\%) & $522(63.1)$ \\
\hline \multicolumn{2}{|l|}{ Race } \\
\hline Caucasian & $688(83.2 \%)$ \\
\hline African American & $15(1.8 \%)$ \\
\hline Other/unknown & $124(15.0 \%)$ \\
\hline \multicolumn{2}{|c|}{ Charlson index at time of $\mathrm{ERCP}^{12}$} \\
\hline Mean (SD) & $3.2(3.2)$ \\
\hline \multicolumn{2}{|l|}{$\mathrm{BMI}$ at time of ERCP } \\
\hline Mean (SD) & $28.5(7.2)$ \\
\hline$<25$ & $341(32.4 \%)$ \\
\hline $25-34$ & $517(49.1 \%)$ \\
\hline $35+$ & $194(18.4 \%)$ \\
\hline
\end{tabular}

10-year period, and the mean number of ERCPs in these patients was 1.3.

\section{Utilisation characteristics}

Average utilisation of ERCP was 83.1 ERCPs/100 000 persons/year, with an increasing trend in utilisation from 58 to 104.8 ERCPs/100 000 persons/year over the 10-year period. Therapeutic ERCPs increased over the same time frame from 42.9 to 93.9 ERCPs/100 000 persons/year (average 68.7). However, diagnostic ERCPs decreased slightly from 15.1 to 10.9 and averaged 14.4 ERCPs/100 000 persons/year. EUS and MRCP utilisation in the same population also steadily increased over this time period (figure 1).

\section{Procedural characteristics}

Procedural characteristics can be seen in table 4 . Of the 1072 ERCPs performed over the 10-year period, 606 (56.5\%) were performed on inpatients, while 889 (82.9\%) were therapeutic. The proportion of therapeutic procedures from 2002 to 2006 was higher than that from 1997 to 2001 ( $86.6 \%$ vs $77.5 \%, \mathrm{p}=0.0001)$. The difficulty grades, as defined by the Morriston Hospital ERCP grading scale, were mostly grade II $(494,46.1 \%)$ and grade III (297, $27.7 \%$ ) procedures overall; however, there was a twofold increase in grade IV procedures in the second 5-year period, compared with the first $(15.3 \%$ vs $7.2 \%$, $\mathrm{p}<0.0001)$. ERCP was performed primarily for a biliary indication in 853 procedures $(79.6 \%)$ and a pancreatic indication in 95 procedures $(8.9 \%)$ with 122 procedures (11.4\%) for both a biliary and pancreatic indication. The commonest biliary indications included choledocholithiasis $(500,46.6 \%)$, biliary colic in the absence of documented choledocholithiasis (307, 28.6\%) and relief of malignant biliary obstruction $(116,10.8 \%)$. The commonest pancreatic indications for ERCP were to determine aetiology of acute pancreatitis $(135,12.6 \%)$, or recurrent acute pancreatitis $(34,3.2 \%)$ and chronic pancreatic fluid collection $(18,1.7 \%)$. Suspected sphincter of Oddi dysfunction was the indication in only $19(1.7 \%)$ ERCPs. A trainee was involved in 667 (62.2\%) cases.

Biliary sphincterotomy was performed in 620 (57.8\%) procedures; the pancreatic duct was injected in 404 $(37.7 \%)$ cases and was cannulated in $255(23.8 \%)$ procedures. In some cases, the intent was to cannulate the bile duct, but pancreatic duct injection occurred during the process. Biliary stents were placed in $185(17.3 \%)$ cases; prophylactic pancreatic stents were placed in 59 $(5.5 \%)$ patients. Placement of pancreatic stents increased in the second 5-year period, compared with the first $(8.1 \%$ vs $1.6 \%, \mathrm{p}<0.0001)$. Ampullectomy was performed in seven $(0.7 \%)$ cases and $16(1.5 \%)$ cases were transgastric or transduodenal debridements of pancreatic necrosis (15 of which occurred in the second 5-year period, $\mathrm{p}=0.0053)$. Only 31 (2.9\%) ERCPs were deemed as failures as the goal of the procedure was not achieved, resulting in a $97.1 \%$ success rate. None of the 
Figure 1 Utilisation characteristics of endoscopic retrograde cholangiopancreatography, endoscopic ultrasound and MR cholangiopancreatography in Olmsted County over a 10-year period.

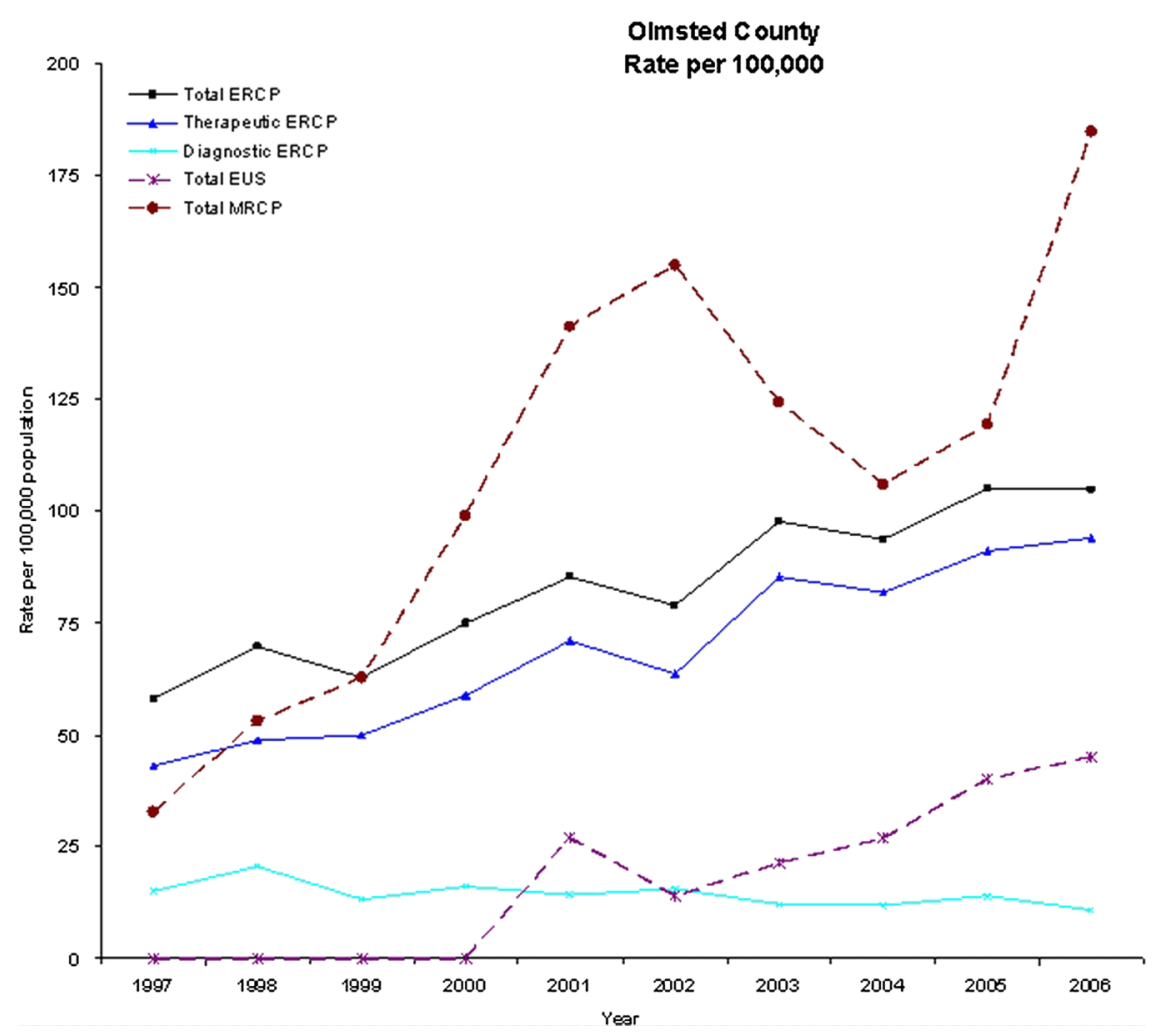

Olmsted c ount

patients received any prophylaxis to prevent post-ERCP pancreatitis (PEP).

\section{Sedation}

Only $42(3.9 \%)$ of procedures were performed with anaesthesia support. Of the remaining ERCPs carried out under moderate sedation, the mean dose of fentanyl was $159 \pm 86 \mu \mathrm{g}$ (in $51 \mathrm{ERCPs}$ ), midazolam $6.1 \pm 2.6 \mathrm{mg}$ (1028 ERCPs), meperidine 97 $\pm 46 \mathrm{mg}$ (979 ERCPs) and promethazine $21 \pm 8 \mathrm{mg}$ (90 ERCPs).

\section{Outcomes}

Following 1072 ERCPs in Olmsted County, over 10 years, there were 273 admissions to the hospital within 30 days after 236 procedures (22\% of all procedures). Table 5 lists the outcomes in the study cohort. Of the 273 admissions, only $62(22.7 \%)$ were definitely related to the index ERCP procedure, with another $2(0.7 \%)$ probably related and $4(1.4 \%)$ possibly related to the procedure. Of the remaining 205 admissions unrelated to procedural AEs of the index ERCP, 79 were planned for elective surgeries, including cholecystectomy. Intraprocedural AEs were infrequent, with $20(1.9 \%)$ necessitating a change in intraprocedural anaesthesia; no deaths occurred during the procedure. There were 47 sphincterotomy-induced intraprocedural bleeding episodes treated with various modalities, including epinephrine injection, cautery and tamponade.

The $\mathrm{AE}$ rate was $5.3 \%$ including pancreatitis (26, $2.4 \%$ ), infection/cholangitis $(16,1.5 \%)$, bleeding (15, $1.4 \%)$ and perforation $(4,0.37 \%)$. Fifty-three cases were determined to be mild to moderate; however, 3 infections, all 4 perforations and 1 bleed were considered severe. The 30-day death rate was $2.4 \% ; 69 \%$ of deaths were due to underlying malignancy, $12 \%$ were due to infections unrelated to ERCP and $19 \%$ were due to other causes including stroke, respiratory failure and dementia. None of the deaths were directly related to ERCP or AEs thereof. Repeat ERCP procedures were required in $93(8.7 \%)$ patients and $45(4.2 \%)$ had an esophagogastroduodenoscopy within 30 days of the index ERCP.

\section{Risk factors for AEs}

In order to determine if there were identifiable risk factors for AEs arising from ERCP in our cohort, the relative frequency and distribution of patient and procedural characteristics were compared between patients who had a procedural AE and those who did not (table 6). Patient characteristics identified through multivariate analysis to be associated with AEs included: age less than 45 years (OR 2.23 (95\% CI 1.03 to 4.84 ) for age $<45$ vs $\geq 65$ years, $\mathrm{p}=0.0498$ ) and BMI $\geq 35$ (OR 0.31 (95\% CI 0.14 to 0.72 ) for BMI 25-34 vs $\geq 35$, $p=0.0024)$. Procedural characteristics identified to be associated with increased risk of AEs included: patient's first ERCP (OR 2.22 (95\% CI 1.04 to 4.75), $\mathrm{p}=0.0394$ ); pancreatic duct cannulation (OR 2.7 (95\% CI 1.4 to 5.1$), \mathrm{p}=0.0026)$; outpatient procedure (OR 5.4 (95\% CI 2.6 to 11.4), p<0.0001); intraprocedure sphincterotomy bleeding (OR 10.0 (95\% CI 3.8 to 26.1), $\mathrm{p}<0.0001)$; difficulty grade (OR 8.9 (95\% CI 1.9 to 43.1 ) for grade 4 vs $1, \mathrm{p}=0.0204$ ). 
Table 4 Procedural characteristics

(\%)

Cholecystectomy within 30 days prior to

\section{ERCP}

Altered anatomy

Anticoagulation

Prior ERCP

Biliary indications

Cholangitis

Cholecystitis

Bleeding

Choledocholithiasis

Malignant stricture

Hilar stricture

Benign stricture

Ca pancreas

Papillary stenosis

Ca ampulla

Anastomotic stricture

Post cholecystectomy

Suspected SOD

PSC

Bile leaks

Biliary colic

Biliary dilation

Stent removal

Elevated AST and ALT

Pancreatic indications

Acute pancreatitis

Recurrent acute pancreatitis

Chronic pancreatitis

Cyst

Duct leak

Duct stricture

Acute fluid collection

Chronic fluid collection

Necrosectomy

Inpatient

Therapeutic

Difficulty grade

I

II

III

IV

Trainee present

Anaesthesia

Conscious sedation

Fentanyl

Versed

Benadryl

Demerol

Phenergan

Droperidol

General (or propofol)

Peri-ampullary diverticulum

Biliary sphincterotomy

Precut biliary sphincterotomy

Biliary stent placed

Pancreatic sphincterotomy

Pancreatic duct stent placed
Table 4 Continued

\begin{tabular}{lr}
\hline & (\%) \\
\hline Ampullectomy & $7(0.7)$ \\
Transgastric/transduodenal drainage & $16(1.5)$ \\
Sphincterotomy bleeding noted during & $45(4.2)$ \\
procedure & \\
\hline ALT, alanine aminotransferase; AST, aspartate aminotransferase; \\
ERCP, endoscopic retrograde cholangiopancreatography.
\end{tabular}

\section{DISCUSSION}

In the adult Olmsted County study population, which is considered to be representative of the US population, ERCP utilisation rates nearly doubled over the 10-year period from 1 January 1997 to 31 December 2006 from 58 to 104.8 cases/100 000 persons/year. ${ }^{15}$ This trend was influenced by a substantial increase in the rate of therapeutic procedures and a slight decrease in diagnostic procedures. Importantly, ERCP was performed predominantly for common 'bread and butter' indications

$19(1.8)$

$21(2)$

$23(2.1)$

$307(28.6)$

$27(2.5)$

$52(4.9)$

$76(7.1)$

217 (20.2)

135 (12.6)

34 (3.2)

$17(1.6)$

$8(0.7)$

$9(0.8)$

$7(0.7)$

$7(0.7)$

$18(1.7)$

$14(1.3)$

606 (56.5)

889 (82.9)

152 (14.2)

494 (46.1)

$297(27.7)$

129 (12.0)

667 (62.2)

1030 (96.1)

$51(4.8)$

1028 (95.8)

$6(0.6)$

979 (91.2)

90 (8.4)

25 (2.3)

42 (3.9)

117 (10.9)

$620(57.8)$

$125(11.7)$

185 (17.3)

$13(1.2)$

59 (5.5)

Continued
Table 5 Procedure outcomes

\begin{tabular}{ll}
\hline Success & (\%) \\
$\begin{array}{l}\text { Death } \\
\text { During procedure }\end{array}$ & $041(97.1)$ \\
$\quad$ Within 30 days & $0(0.0)$ \\
Need for repeat procedure within 30 days & $26(2.4)$ \\
ERCP & $93(8.7)$ \\
EGD & $451(4.2)$ \\
Number of readmissions within 30 days & 273 \\
$\quad$ Definitely related to procedure & $62(22.7)$ \\
Possibly related to procedure & $6(2.2)$ \\
Definitely not related to procedure & $205(75.1)$
\end{tabular}

Surgery within 30 days

Elective cholecystectomy 52 (4.9)

Elective Whipple

$16(5.9)$

11 (4.0)

$6(2.2)$

Emergent cholecystectomy

53 (4.9)

Pancreatitis

26 (2.4)

Mild 18

Moderate $\quad 8$

Severe

0

Mild 6

Moderate $\quad 7$

Severe 3

Bleeding

Mild

$15(1.4)$

Moderate

6

Severe

Perforation

Mild

Moderate

0

Severe

4

EGD, esophagogastroduodenoscopy; ERCP, endoscopic retrograde cholangiopancreatography.
Infection/cholangitis 
Table 6 Multivariate analysis of risk factors for post-ERCP complications

\begin{tabular}{lcc}
\hline Risk factor & Odds ratio (95\% Cl) & p Value \\
\hline Age $<45$ vs $\geq 65$ & $2.23(1.03$ to 4.84$)$ & $0.0498^{*}$ \\
Age 45-64 vs $\geq 65$ & $1.3(0.62$ to 2.72$)$ & 0.6697 \\
Female gender & $1.2(0.61$ to 2.21$)$ & 0.6412 \\
BMI $<25$ vs $\geq 35$ & $0.84(0.40$ to 1.74$)$ & 0.1972 \\
BMI 25-34 vs $\geq 35$ & $0.31(0.14$ to 0.72$)$ & $0.0024^{*}$ \\
No previous ERCP & $2.22(1.04$ to 4.75$)$ & $0.0394^{*}$ \\
Outpatient ERCP & $5.4(2.6$ to 11.4$)$ & $<0.0001^{*}$ \\
Pancreatic duct cannulation & $2.7(1.4$ to 5.1$)$ & $0.0026^{*}$ \\
Absence of trainee & $1.36(0.72$ to 2.59$)$ & 0.3487 \\
Intraprocedure sphincterotomy bleeding & $10.0(3.8$ to 26.1$)$ & $<0.0001^{*}$ \\
Difficulty grade 1 vs 4 & $0.11(0.02$ to 0.54$)$ & $0.0204^{*}$ \\
Difficulty grade 2 vs 4 & $0.45(0.18$ to 1.14$)$ & 0.9199 \\
Difficulty grade 3 vs 4 & $0.94(0.42$ to 2.13$)$ & $0.0129^{*}$ \\
\hline${ }^{*}$ p-Value $<0.05$. &
\end{tabular}

including cholangitis, biliary colic and pancreatitis. This information underscores the fact that ERCP is currently mainly a therapeutic modality, and should be available at a community-based level. Training in ERCP should be focused on gaining expertise mainly for removal of common duct stones and relief of distal biliary obstruction. For a community-based gastroenterologist, the need for more complex procedures is rare, and these procedures should be carried out at tertiary care centres.

ERCP utilisation rates in Olmsted County in this study are in some ways divergent from national data. For instance, Mazen Jamal et $a l^{16}$ queried the Nationwide Inpatient Sample (NIS) data for ERCP utilisation rates from 1996 to 2002. They found that the rate of inpatient ERCPs dropped from 74.95/100 000 persons in 1996 to $59.70 / 100000$ in 2002, driven mostly by a decrease in diagnostic procedures, while there was a slight concomitant increase in therapeutic procedures. However, because they were using an NIS sample, data are not available on outpatient utilisation of ERCP. In contrast, outpatient procedures comprised $43.5 \%$ of procedures in our study.

Over the study period, overall utilisation of EUS and MRCP have also increased in Olmsted County. ERCP is most likely utilised now almost exclusively for therapeutic purposes because of the diagnostic abilities of EUS and MRCP, and the improvements in contrast-enhanced CT scans. Also, increased use of EUS and MRCP might actually result in more therapeutic ERCP as seen in our study, which contradicts the popular belief that utilisation of ERCP has decreased over time with the increased use of other diagnostic modalities.

Unplanned admissions commonly occur after ERCP ( $22 \%$ within 30 days), but are most often not related to procedural AEs, which occur in $5.3 \%$ of all patients undergoing ERCP. Unplanned admissions within 30 days after a procedure are increasingly being counted as negative indicators of healthcare quality. ${ }^{17}$ However, our data suggest that in the case of ERCP, this outcome measure may not be a valid indicator of the quality of the procedure itself and is most likely related to either underlying disease, a finding of the procedure itself that leads to elective surgery, or possibly to other comorbidities. Identification and complete capture of 30-day admissions is one of the strengths of our study, in comparison to past studies, where capturing remote AEs were incomplete. ${ }^{6}$ Because this is a population-based study, and Mayo Clinic is the only provider for ERCP in the population, all AEs were identified.

Severe procedural AEs, including pancreatitis $(2.4 \%)$, bleeding $(1.5 \%)$, infection $(1.4 \%)$ and mortality related to the procedure $(0 \%)$, were uncommon. Most AEs were mild to moderate, and at rates similar to previously published reports. ${ }^{3}{ }^{6}$ In a systematic review of 21 surveys of ERCP, AE rates in a population of 16855 patients were $6.85 \%$, with pancreatitis, infection and bleeding occurring in $3.5 \%, 1.4 \%$ and $1.3 \%$ of cases; ${ }^{3}$ the death rate was $0.33 \%$. Cotton et al reported on 11497 procedures at multiple centres and found a $4 \% \mathrm{AE}$ rate, with rates of $2.6 \%$ for pancreatitis and $0.3 \%$ for bleeding. The death rate in this cohort was $0.06 \% .^{6}$ Although $2.4 \%$ of patients in our study died within 30 days of ERCP, none of these deaths were ERCP-related, and there were no intraprocedural or peri-procedural deaths in our study. Because the AE rates in our study are similar to the rates reported in the literature, it is most likely that the ERCP procedures carried out at other tertiary care centres are also associated with low AE rates.

Numerous studies have enumerated various risk factors for AEs following ERCP. ${ }^{6} 101819$ The commonly accepted risk factors for any AE after ERCP include suspected sphincter of Oddi dysfunction, cirrhosis, difficult cannulation, performance of precut sphincterotomy, percutaneous biliary access and lower ERCP case volumes, with young age, pancreatic duct contrast injection and failed biliary drainage identified in some 
studies. In our study, younger patient age, higher BMI, first ERCP, pancreatic duct cannulation, intraprocedural post sphincterotomy bleeding, therapeutic procedures and outpatient procedures were identified as risk factors for any AE through a multivariate analysis.

Consistent with our findings, younger age has been previously shown to be a risk factor for AEs, especially post-PEP. ${ }^{5}{ }^{10}$ Pancreatic duct cannulation is known to be a risk-factor for development of PEP. ${ }^{6}$ Towards the end of this study period, data emerged supporting the use of prophylactic pancreatic duct stents to decrease the incidence of PEP and were published. In our study period, in only $59(5.5 \%)$ procedures, we placed a pancreatic duct stent. Hence, our study is not able to adequately define the rate of PEP with routine placement of prophylactic pancreatic stents.

One limitation of our study is that it is a retrospective review of data with its inherent biases. However, the data were manually abstracted by a single gastroenterologist from an electronic medical record, and significant AEs and hospitalisations are not likely to have been missed. Another limitation is that even though the population studied is a county-based population, the skills of the endoscopists are at a higher level than those of endoscopists in smaller community hospitals. Therefore, the $\mathrm{AE}$ rate in this community setting could be lower than one would expect in community settings at large. While MRCP is widely available, wherever MRI is available, EUS availability is limited to those centres with trained endosonographers; it is possible that the latter may affect regional utilisation of ERCP for diagnostic purposes. Another notable limitation is that Sphincter of Oddi dysfunction and complications of pancreatitis, diagnoses often referred to a tertiary centre, were underrepresented in our study.

In conclusion, our study shows that utilisation of ERCP at a population level continues to rise; specifically utilisation of therapeutic procedures. The most common indications for ERCP remain relief of biliary colic or cholangitis, and this procedure may be carried out with moderate sedation. AEs of ERCP remain uncommon and deaths are infrequent. The study adds important epidemiological data on trends in the utilisation of ERCP, as well as population-based estimates of the risk of AEs from ERCP that will be useful in clinical decisionmaking and determination of resource allocation. The findings of the study may also impact ERCP training criteria.

Acknowledgements This publication was supported by NIH/NCRR CTSA Grant Number UL1 RR024150. Its contents are solely the responsibility of the authors and do not necessarily represent the official views of the NIH.

Contributors NC-P participated in the conception and design; analysis and interpretation of the data; drafting of the article; final approval of the article. NDS participated in the conception and design; analysis and interpretation of the data; critical revision of the article for important intellectual content. HVH participated in the analysis and interpretation of the data. PSK participated in the conception and design; critical revision of the article for important intellectual content. THB participated in the conception and design; critical revision of the article for important intellectual content; final approval of the article.

Funding This research received no specific grant from any funding agency in the public, commercial or not-for-profit sectors.

Competing interests None.

Ethics approval Mayo Clinic IRB.

Provenance and peer review Not commissioned; externally peer reviewed.

Data sharing statement Any additional data can be obtained from the corresponding author. This includes procedural details on all ERCPs including patient characteristics, indication, sedation, trainee involvement, therapies utilised during the ERCP, complications, billing codes.

\section{REFERENCES}

1. McCune WS, Shorb PE, Moscovitz H. Endoscopic cannulation of the ampulla of vater: a preliminary report. Ann Surg 1968;167:752-6.

2. Adler DG, Baron TH, Davila RE, et al. ASGE guideline: the role of ERCP in diseases of the biliary tract and the pancreas. Gastrointest Endosc 2005;62:1-8.

3. Andriulli A, Loperfido S, Napolitano G, et al. Incidence rates of post-ERCP complications: a systematic survey of prospective studies. Am J Gastroenterol 2007;102:1781-8.

4. Bodger K, Bowering K, Sarkar S, et al. All-cause mortality after first ERCP in England: clinically guided analysis of hospital episode statistics with linkage to registry of death. Gastrointest Endosc 2011;74:825-33.

5. Christensen M, Matzen P, Schulze S, et al. Complications of ERCP: a prospective study. Gastrointest Endosc 2004;60:721-31.

6. Cotton PB, Garrow DA, Gallagher J, et al. Risk factors for complications after ERCP: a multivariate analysis of 11,497 procedures over 12 years. Gastrointest Endosc 2009;70:80-8.

7. Glomsaker T, Soreide K, Hoff G, et al. Contemporary use of endoscopic retrograde cholangiopancreatography (ERCP): a Norwegian prospective, multicenter study. Scand J Gastroenterol 2011;46:1144-51.

8. Loperfido S, Angelini G, Benedetti G, et al. Major early complications from diagnostic and therapeutic ERCP: a prospective multicenter study. Gastrointest Endosc 1998;48:1-10.

9. Sieg A, Hachmoeller-Eisenbach U, Eisenbach T. Prospective evaluation of complications in outpatient GI endoscopy: a survey among German gastroenterologists. Gastrointest Endosc 2001;53:620-7.

10. Masci E, Toti $\mathrm{G}$, Mariani $\mathrm{A}$, et al. Complications of diagnostic and therapeutic ERCP: a prospective multicenter study. Am J Gastroenterol 2001;96:417-23.

11. Talley NJ, Jones M. Self-reported rectal bleeding in a United States community: prevalence, risk factors, and health care seeking. $\mathrm{Am} \mathrm{J}$ Gastroenterol 1998;93:2179-83.

12. Charlson ME, Pompei $\mathrm{P}$, Ales $\mathrm{KL}$, et al. A new method of classifying prognostic comorbidity in longitudinal studies: development and validation. J Chron Dis 1987:40:373-83.

13. Ragunath K, Thomas LA, Cheung WY, et al. Objective evaluation of ERCP procedures: a simple grading scale for evaluating technical difficulty. Postgrad Med J 2003;79:467-70.

14. Cotton PB, Lehman G, Vennes J, et al. Endoscopic sphincterotomy complications and their management: an attempt at consensus. Gastrointest Endosc 1991;37:383-93.

15. St Sauver JL, Grossardt BR, Leibson CL, et al. Generalizability of epidemiological findings and public health decisions: an illustration from the Rochester Epidemiology Project. Mayo Clin Proc 2012;87:151-60.

16. Mazen Jamal M, Yoon EJ, Saadi A, et al. Trends in the utilization of endoscopic retrograde cholangiopancreatography (ERCP) in the United States. Am J Gastroenterol 2007;102:966-75.

17. Jencks SF, Williams MV, Coleman EA. Rehospitalizations among patients in the medicare fee-for-service program. $N$ Engl J Med 2009;360:1418-28.

18. Freeman ML. Understanding risk factors and avoiding complications with endoscopic retrograde cholangiopancreatography. Curr Gastroenterol Rep 2003;5:145-53.

19. Freeman ML, Nelson DB, Sherman S, et al. Complications of endoscopic biliary sphincterotomy. N Engl J Med 1996;335:909-18. 